\title{
Charlson Comorbidity Index as a Strong Predictor of Mortality in Patients with Chronic Hemodialysis
}

\author{
Tayebeh Soleymanian ${ }^{1, *}$, Zahra Ghaziani ${ }^{2}$ \\ ${ }^{1}$ Associate Professor, Department of Nephrology, Shariati Hospital, Tehran University of Medical Sciences, Tehran, Iran \\ ${ }^{2}$ Resident of Internal Medicine, Shariati Hospital, Tehran University of Medical Sciences , Tehran, Iran
}

* Corresponding Author: Tayebeh Soleymanian, Department of Nephrology, Shariati Hospital, Tehran University of Medical Sciences, Tehran, Iran.Email: soleymanian@tums.ac.ir

Received: 19.07 .2018

Accepted: 10.11 .2018

\section{How to Cite this Article:}

Soleymanian T, Ghaziani Z Charlson Comorbidity Index as a Strong Predictor of Mortality

in Patients with Chronic Hemodialysis. Avicenna J Clin Med. 2018; 25(3): 151-158. DOI: $10.21859 /$ ajcm.25.3.151

\section{Abstract}

Background and Objective: Mortality of hemodialysis patients is still high, which can be estimated using the Charlson Comorbidity Index (CCI) and serum albumin.

Materials and Methods: This prospective cohort study was conducted on adult chronic hemodialysis patients $(n=532)$ from 9 hemodialysis (HD) facilities in September 2012. The obtained data included demographic factors and laboratory data, which consisted of serum albumin and patients' comorbidities at the beginning of study, as well as the causes of mortality, hospitalization, and termination of hemodialysis in a 28-month follow-up period. Furthermore, one- and two-year survival of patients was evaluated by CCI and the age of patients was estimated by serum albumin $\geq 3.5 \mathrm{~g} / \mathrm{dL}$ and serum albumin $<3.5 \mathrm{~g} / \mathrm{dL}$.

Results: The mean age of patients was $56 \pm 15.4$ years. The participants consisted of $57 \%$ men, $41 \%$ diabetes, and $43 \%$ ischemic heart disease. The mean of dialysis vintage was $44.6 \pm 49.1$ months. The mean values were $10.6 \pm 1.50 \mathrm{~g} / \mathrm{dl}, 3.90 \pm 0.35 \mathrm{~g} / \mathrm{dl}$, and $1.31 \pm 0.21$ for serum hemoglobin, serum albumin, and dialysis treatment adequacy $(\mathrm{Kt} / \mathrm{V}$; i.e., $\mathrm{K}=$ Clearance Dialyzer, $\mathrm{T}=$ Time, $\mathrm{V}=$ Volume of Distribution of Urea), respectively. A total of 161 (30\%) patients passed away (17 per 100 patient a year), and the most common causes of mortality were cardiovascular diseases (42\%) and infections (25\%). In Cox proportional hazard model, hazard ratio (HR) of death was 1.03 year (95\% CI: 1.01-1.05; $\mathrm{P}=0.007)$, for serum albumin (g/dL) was 0.21 (95\% CI: 0.11-0.40; $\mathrm{P}<0.001$ ), and for CCI was 1.75 (95\% CI: 1.59-1.94; $\mathrm{P}<0.001)$. One-year survival probability for patients in the group A (serum albumin $\geq 3.5 \mathrm{~g} / \mathrm{dL}$ ) with CCI scores $2-3,4-5,6-7$, and $\geq 8$ were $96 \%, 92 \%, 81 \%$, and $64 \%$, respectively. However, these numbers for patients in group B (serum albumin $<3.5 \mathrm{~g} / \mathrm{dL}$ ) were $86 \%, 75 \%, 60 \%$, and $42 \%$, respectively. Two-year survival probability for patients in group A with CCI scores $2-3,4-5,6-7$, and $\geq 8$ were $94 \%, 89 \%, 73 \%$, and $36 \%$, respectively. Furthermore, the obtained results for patients in group B were $86 \%, 45 \%, 39 \%$ and $22 \%$, respectively.

Conclusion: Charlson Comorbidity Index along with serum albumin and age are appropriate variables to predict one- and two-year survival of HD patients. Therefore, there is a need to take appropriate measures for high risk patients to improve their health status.

Keywords: Comorbidity, Hemodialysis, Mortality, Serum Albumin 


\section{اندكس كوموربيديتى جار للسون بهعنوان فاكتور بيش تويى كننده قوى مرتى و مير در بيماران همودياليز مزمن بن بون}

\section{طيبه سليمانيان إ:، زهرا قاضيانى}

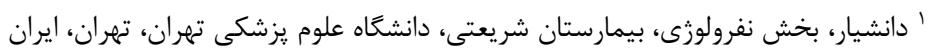

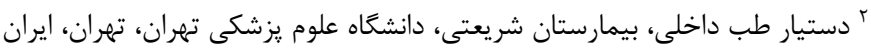

* : نويسنده مسئول: طيبه سليمانيان، بخش نفرولوزى، بيمارستان شريعتى، دانشعاه علوم بزشكى تهران، تهران، ايران. ايميل: soleymanian@tums.ac.ir

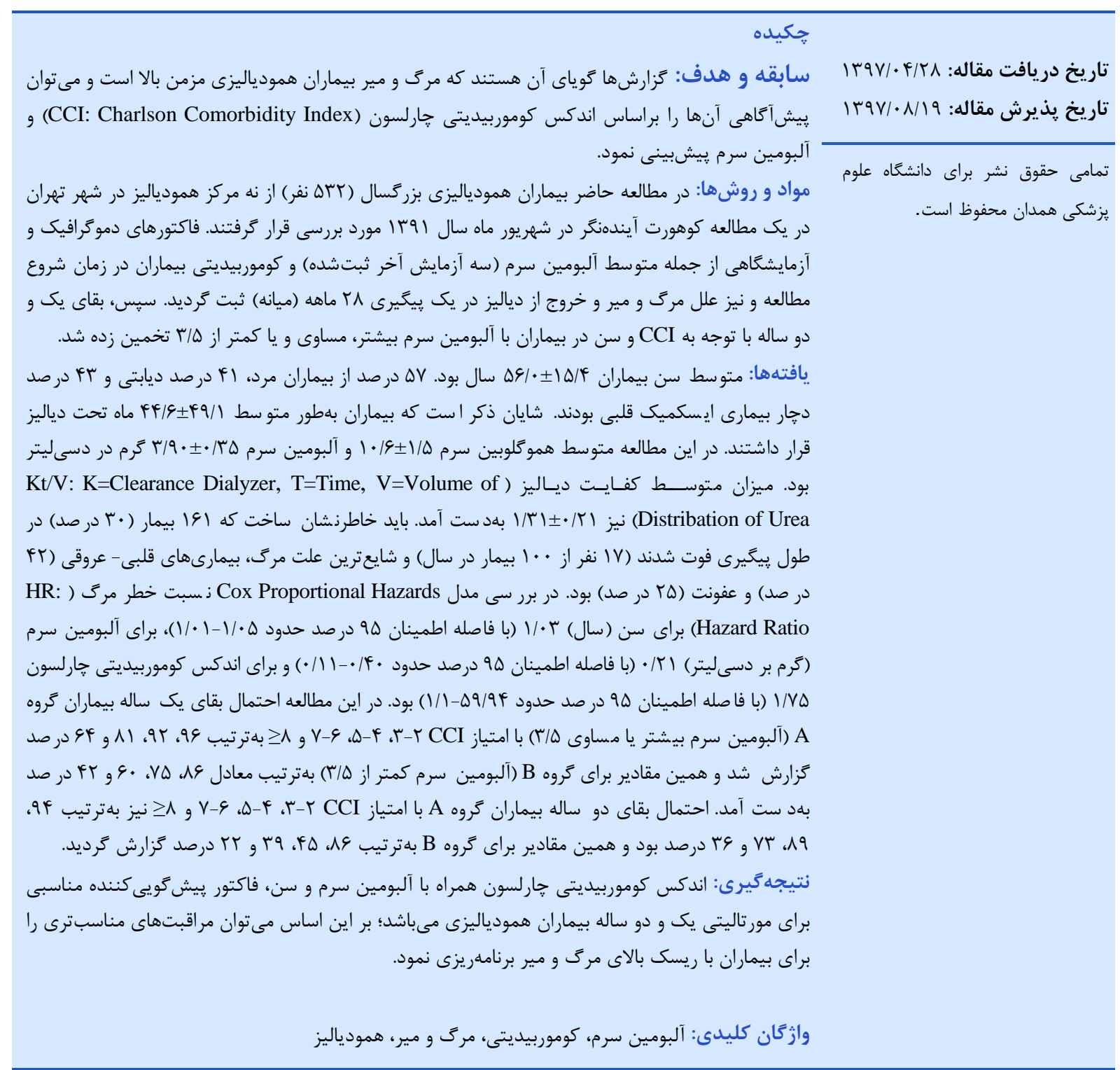

فاكتورها همانند سن، آلبومين سرم، نوع دسترسى عروقى، فسفر

بيماران دياليزى با ميزان بالاترى از سوءتغذيه، التهاب و و
مرك و مير در بيماران دياليزى بالا است و اين امر تا حد

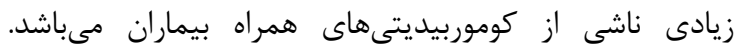

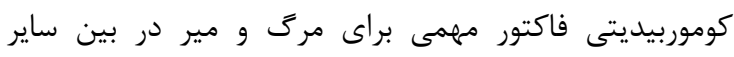


Renal Disease)، وزن خشك بيماران، قد، فشار خون قبل و بعد از دياليز، نوع دسترسى عروقى، كوموربيديتى هاى جارلسون، كفايت

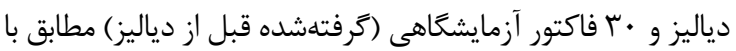

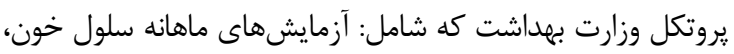

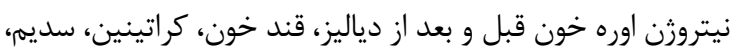

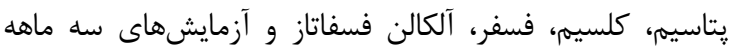
آلبومين، جربى، آهن، ترانسفرين، فريتين، هورمون ياراتيروئيد، آنزيمهاى كبدى، يروتئين التهابى C-Reactive Protein) CRP)

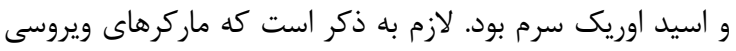
بلهورت شش ماهه جك گرديد. علاوهبراين، حداقل دو يا سه

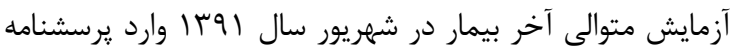

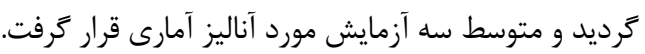

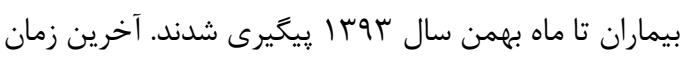

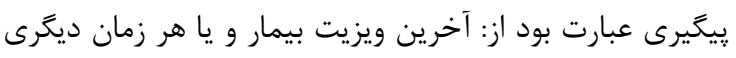

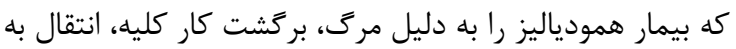

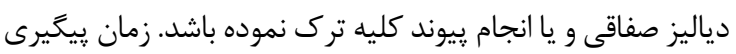

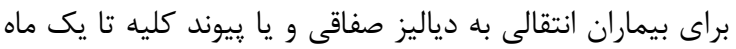

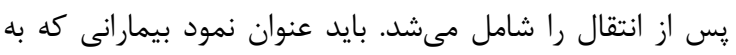

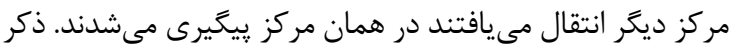

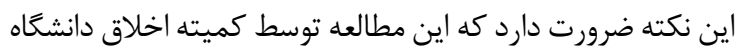

مورد تأييد قرار گرفت و رضايت آكاهانه از بيماران اخذ كرديد.

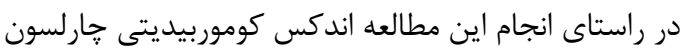

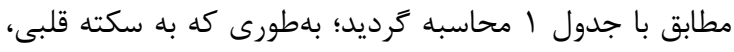

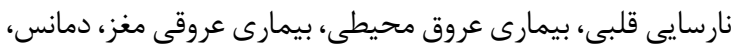

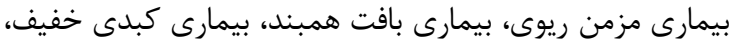

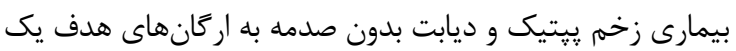

بيمارىهاى زمينهاى همراه مواجه هستند؛ بنابراين، ميزان

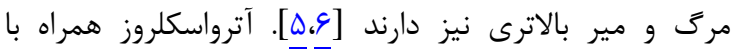
كالسيفيكاسيون عروقى و افزايش حجم باعث مرگ و مير مير بالاتر

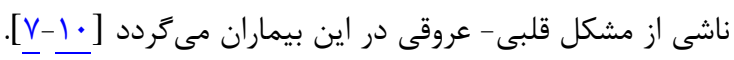

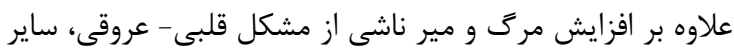

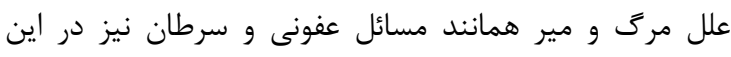

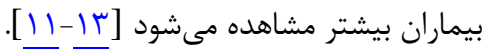

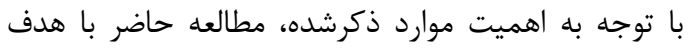

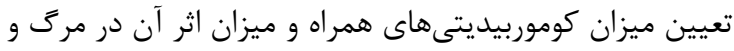

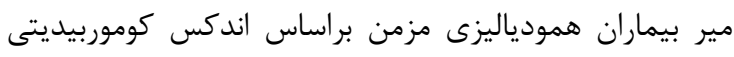

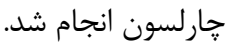

\section{مواد و روش ها}

در مطالعه كوهورت آيندهنگر مولتى سنتر حاضر بسه بيمار

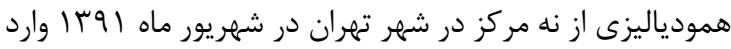

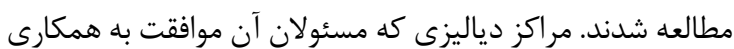

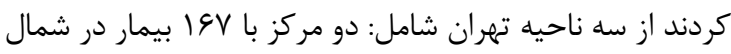

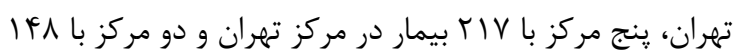

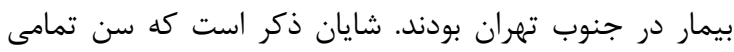

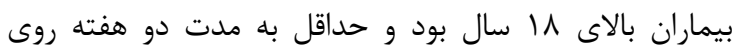

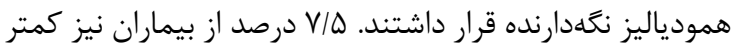
از سه ماه همودياليز شده بودند.

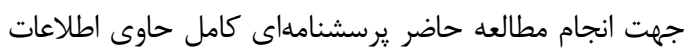

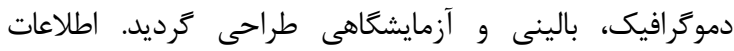
يرسشنامه عبارت بودند از: تاريخ تولد، جنس، وضعيت تأهل، ميزئن تحصيلات، شغل، علت نارسايى كليه ( ESRD: End Stage

جدول ا: سيستم امتيازدهى اندكس كوموربيديتى خارلسون

\begin{tabular}{|c|c|}
\hline حالت & 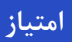 \\
\hline 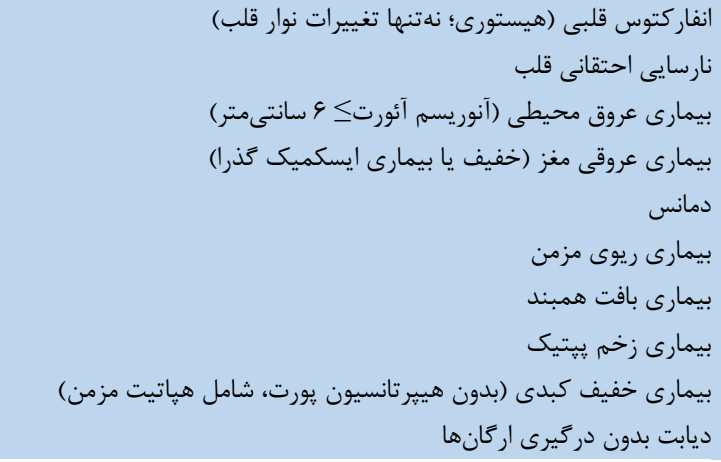 & 1 \\
\hline 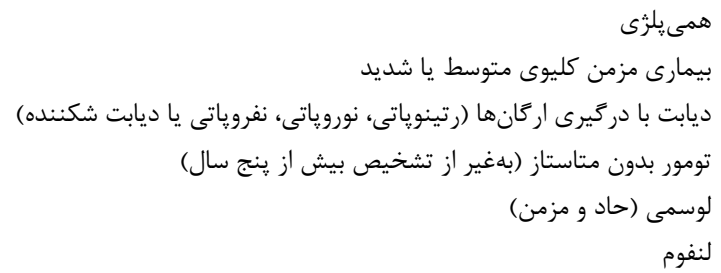 & $r$ \\
\hline بيمارى كبدى متوسط يا شديد & r \\
\hline تومور متاستاتيك اركانها HIV مثبت) & 9 \\
\hline
\end{tabular}


يلى كيستيك غالب كليوى (r درصد)، بيمارىهاى ديگر ارثى (D/ه

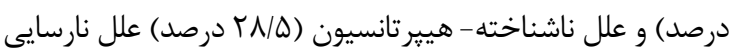

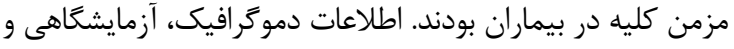

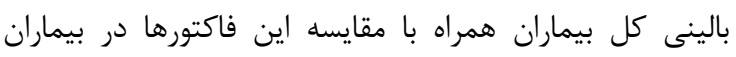

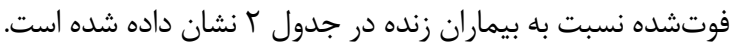

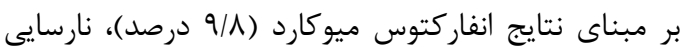

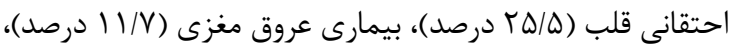

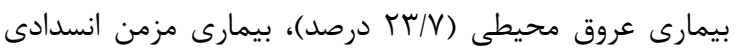

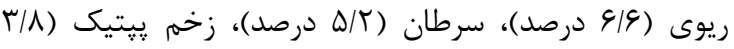

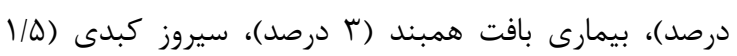
درصد) و دمانس (T/ إ درصد) علل شايع كوموربيديتى بودند.

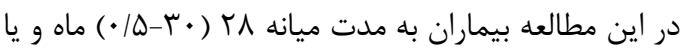

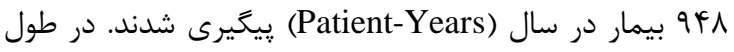

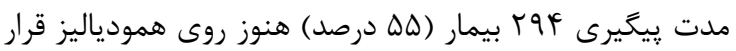

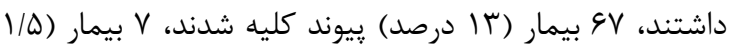

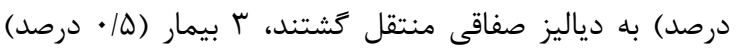

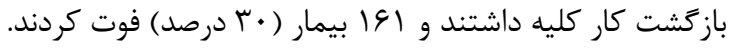

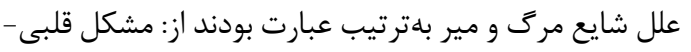

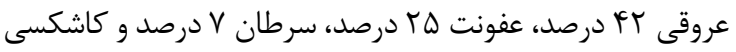
4 درصد. شايان توجه است كه مورتاليتى قلبى- عروقى اثر عردئ

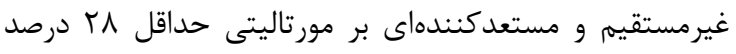

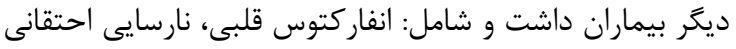
قلب، حوادث عروق مغزى و ايست ناتحانى قلب بود.

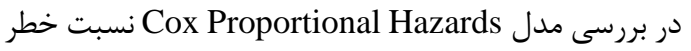

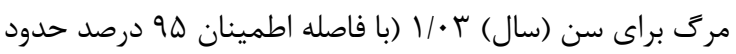

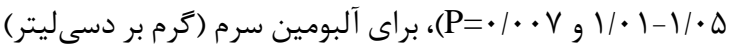

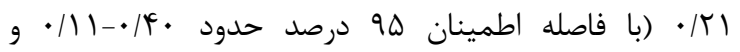

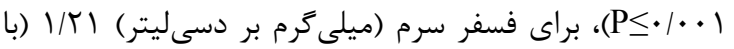

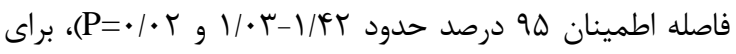

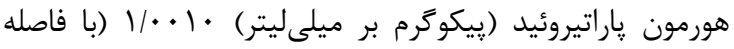

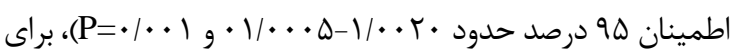
كاتتر همودياليز (در مقايسه با فيستول) 1/D (با فاصله اطمينان

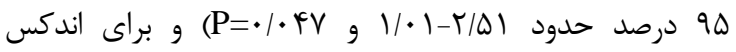

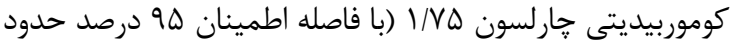

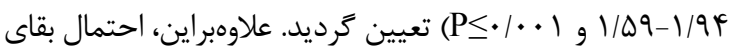

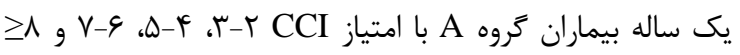

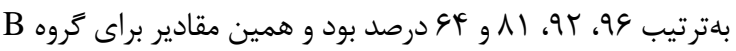

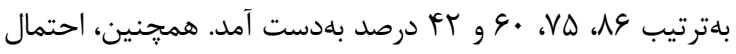

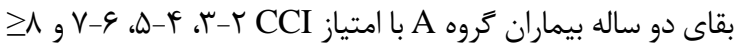
بلترتيب \&

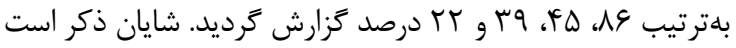

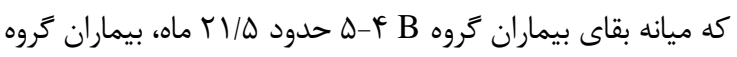
ح ح-9 B

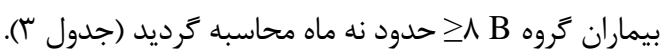

امتياز؛ به همى ثلزى، نارسايى متوسط تا شديد كليوى، ديابت با

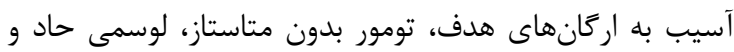

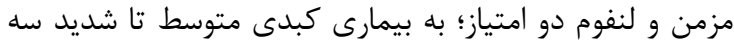

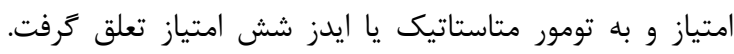

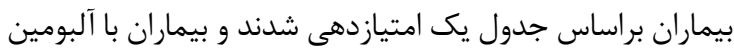

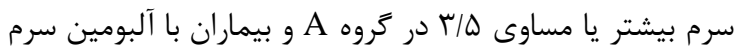

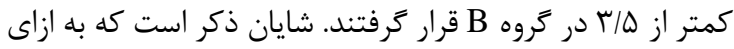
هريك دهد افزايش سن مساوى يا بيشتر از • له سال، يك امتياز به CCI اضافه مى گرديد. اطلاعات پرسشنامه با گرفتن شرح حال، استفاده از يرونده

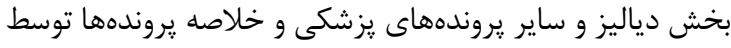

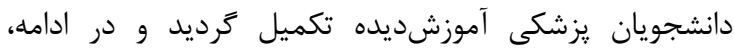

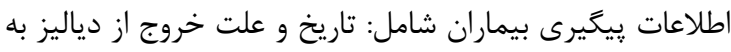

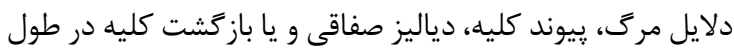

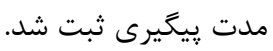

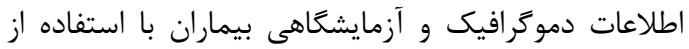
درصد كل، متوسط (بانحراف معيار) و يا ميانه ( Interquarter

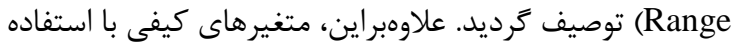

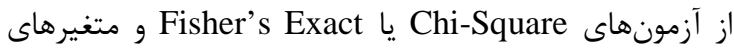
كمى توسط Mann-Whitney U يا t-test مقايسه كرديدند. از مدون مدل Cox Proportional Hazard نيز جهت بررسى نسبت

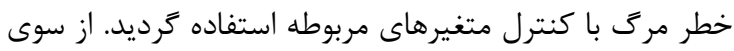

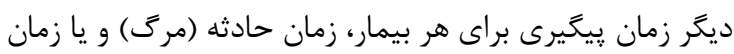

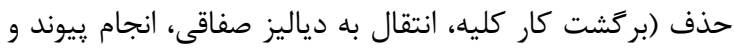

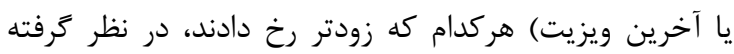

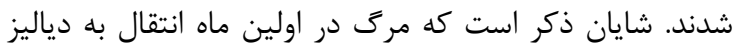

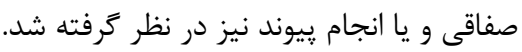

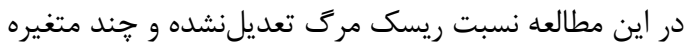
تعديلشده ( Unadjusted and Incremental Levels of

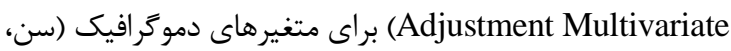

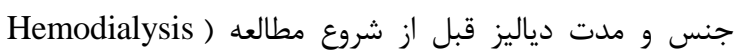

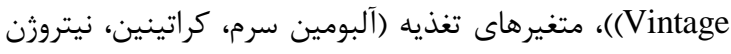

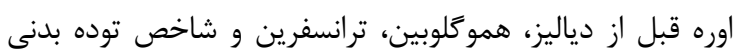

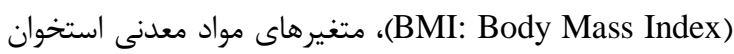

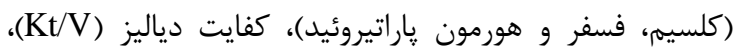

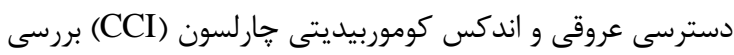

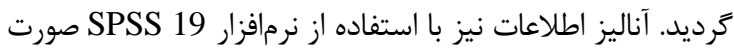
يذيرفت و مقدار ه • P P معنادار در نظر كرفته شد.

بافته ها

متوسط سن بيماران

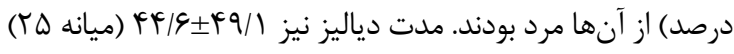

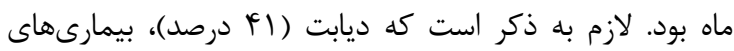

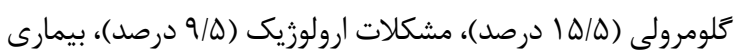


جدول r: اطلاعات دموَرافيك، بالينى و آزمايشكاهى بيماران همودياليزى زنده و فوتشده مورد مطالعه

\begin{tabular}{|c|c|c|c|c|}
\hline سطح معنادارى & فوتشده (اצا نفر) & 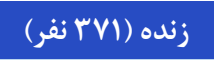 & 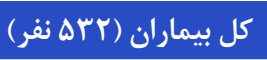 & 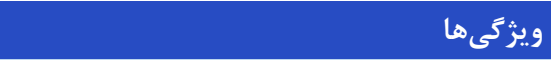 \\
\hline$\cdot 119$ & $\Lambda F(\Delta Y)$ & $r \mid \wedge(\Delta q)$ & $r \cdot r(\Delta V)$ & جنس (مذكر؛ درصد) \\
\hline$<\cdot / \cdot \cdot 1$ & $9 \mu / V \pm I r / T$ & $\Delta r / \Lambda \pm 1 \Delta / r$ & $\Delta \varphi / \cdot \pm \mid \Delta / \uparrow$ & سن (سال) \\
\hline$\cdot / \mu r$ & $9 \Delta / \Delta \pm \mid f / q$ & $\varphi q|\Lambda \pm| f / \mid$ & $\varphi q / \Delta \pm \mid q / \pi$ & وزن (كيلو ترم) \\
\hline$\cdot / \mu r$ & $\operatorname{TF}(\Lambda / \Delta \cdot-G M / \Delta)$ & $r \Delta(11-9 \Lambda)$ & $r \Delta(11-99)$ & زمان روى دياليز (ماه) \\
\hline$<\cdot / \cdot \cdot 1$ & $f(r-\omega)$ & $1(\cdot-r)$ & $r(\cdot-r)$ & (بدون امتياز سن و دروريديتى جارلسون كليه) \\
\hline$<\cdot / \cdot \cdot 1$ & $91(\Delta \& / \Delta)$ & $I T \Lambda(K Y / Q)$ & $r 19(F 1)$ & ديابت (بله؛ درصد) \\
\hline .194 & $r \Psi / F \pm \Delta / r$ & $r F / F \pm F / r$ & $r F / F \pm r / q$ & اندكس وزن بدن (BMI) (كيلوكرم بر متر مربع) \\
\hline & & & & يافتههاى آزمايشگاهى (سرم) \\
\hline$<\cdot / \cdot \cdot 1$ & $r / V I \pm \cdot / r$ & $r / 99 \pm \cdot / r r$ & $r / q \cdot \pm \cdot / r \Delta$ & آلبومين (َرم بر دسىليتر) \\
\hline$\cdot \pi t$ & $1 \cdot / f \pm 1 / \Delta$ & $1 \cdot 19 \pm 1 / 0$ & $1 \cdot 19 \pm 1 / 0$ & هموكلوبين (كرم بر دسىليتر) \\
\hline$\cdot / \cdot r$ & $\mid F V \pm V \varepsilon$ & $|r| \pm V r$ & $1 r \varepsilon \pm V r$ & قند (ميلى گرم بر دسىليتر ) \\
\hline $.1 \cdot 9$ & $|f| \pm V r$ & $|\Delta \Delta \pm \Lambda|$ & $|\Delta| \pm V q$ & ترى كليسريد (ميلى گرم بر دسىليتر ) \\
\hline$<\cdot / \cdot \bullet$ & $V / V \pm T / r$ & $9 / 1 \pm r / 9$ & $\Lambda / \varepsilon \pm r / \Lambda$ & كراتينين (ميلى \\
\hline$\cdot / \cdot r$ & $\Delta F / \Delta \pm I r / q$ & $\Delta V / r \pm I r / 9$ & $\Delta \varepsilon / \mathcal{F} \pm I r / \Delta$ & اوره- نيتروزن خون (ميلى گرم بر دسىليتر ) \\
\hline.$/ 14$ & $1 / T \wedge \pm \cdot / T$ & $|/ T r \pm \cdot / T|$ & $|/ r| \pm \cdot|r|$ & كفايت دياليز \\
\hline$\cdot / 4$ & $\Delta / 1 \pm \cdot 19$ & $\Delta / T \pm \cdot / \varphi$ & $\Delta / T \pm \cdot / V$ & يتاسيم (ميلىاكى والان بر ليتر ) \\
\hline$\cdot / \mu r$ & $\wedge / \Lambda \pm \cdot / V$ & $\wedge / q \pm \cdot / V$ & $\wedge / 9 \pm \cdot / \Lambda$ & كلسيم (ميلى گرم بر دسىليتر) \\
\hline$\cdot / \mu$ & $\Delta / \Delta \pm 1 / \Gamma$ & $\Delta / \Delta \pm 1 / r$ & $\Delta / \Delta \pm 1 / r$ & فسفر (ميلى گرم بر دسىليتر) \\
\hline$\cdot / r V$ & $r \cdot 1(\mid F V-q \cdot r)$ & 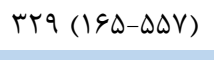 & $r T \cdot(\mid \Delta \Lambda-\Delta V T)$ & هورمون پاراتيروئيد (ييكوَرم بر ميلىليتر) \\
\hline \multirow{5}{*}{$<\cdot / \cdot \cdot 1$} & & & & بيمارى ايسكميك قلبى \\
\hline & $R T(T V)$ & rel $(V \cdot \mid Q)$ & $r \cdot F(\Delta V)$ & ت تعداد (درصد) \\
\hline & $\Lambda F(\Delta r)$ & $\Delta \Delta(1 \Delta)$ & $1 \% q(Y \varepsilon)$ & درمان مديكال تعداد (درصد) \\
\hline & $V(q)$ & $Y I(\Delta / \Delta)$ & $r \wedge(\Delta / \Delta)$ & 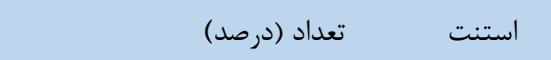 \\
\hline & $r V(I V)$ & re (q) & G) $(1 / / \Delta)$ & جراحى باز قلب تعداد (درصد) \\
\hline \multirow{4}{*}{$\cdot 1 \cdot \cdot 1$} & & & & دسترسى عروقى همودياليز \\
\hline & $99(9) / \Delta)$ & 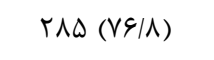 & rAF (VT) & فيستول شريانى - وريدى تعداد (درصد) \\
\hline & If $(\Lambda / V)$ & $r(\varepsilon / r)$ & $r V(V)$ & كرافت شريانى - وريدى تعداد (درصد) \\
\hline & $\varphi \wedge(r q / \Lambda)$ & $g r(I V)$ & $111(Y 1)$ & تعداد (درصد) \\
\hline
\end{tabular}

جدول ب: احتمال بقاى يك ساله و دو ساله بيماران براساس اندكس كوموربيديتى جارلسون و آلبومين سرم

\begin{tabular}{|c|c|c|c|}
\hline (فاصله اطمينان هاى دو درصد) & (فاصله اطمينان هو يك ساله درصد) & تعداد (درصد) & 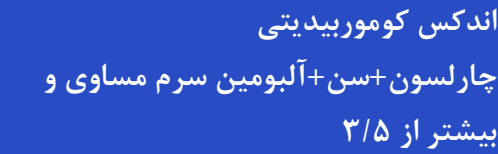 \\
\hline$\cdot / 94(\cdot 119-\cdot / 99)$ & $\cdot / 99(\cdot / 94-\cdot / 99)$ & $1 \% q(T \varphi)$ & $r-r$ \\
\hline$\cdot / 19(\cdot / 11-\cdot / 9 \vee)$ & $\cdot / 94(\cdot / 19-\cdot / 91)$ & $119(T T)$ & $f-\omega$ \\
\hline$\cdot / \mathrm{Nr}^{\mathrm{N}}\left(\cdot\left|9 \varphi_{-} \cdot\right| \mathrm{A} \cdot\right)$ & $\cdot|\Lambda|\left(\cdot\left|V F_{-} \cdot\right| \Lambda \Lambda\right)$ & זr(T) & $4-V$ \\
\hline$\cdot / K^{\prime}\left(\cdot / T_{-} \cdot / \Delta \cdot\right)$ & $\cdot \mid G 4(\cdot|\Delta|-\cdot \mid V Y)$ & $q \cdot(I V)$ & مساوى و بيشتر از 1 \\
\hline & & & 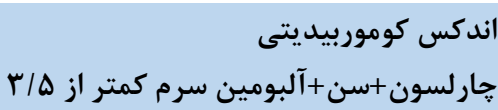 \\
\hline$\cdot \operatorname{l19}(\cdot 199-1 / \cdot \cdot)$ & $\cdot \operatorname{l19}(\cdot \mid 99-1 / \cdot \cdot)$ & $V(1 / \Gamma)$ & $r-r$ \\
\hline$\cdot / F \Delta(\cdot / T r-\cdot / V \nabla)$ & $\cdot / 9 T(\cdot / 0 F-\cdot / 94)$ & $\Lambda(1 / \Delta)$ & $f-\omega$ \\
\hline$\cdot / r q\left(\cdot / / \Delta_{-} \cdot \mid q \mu\right)$ & $\cdot|\wedge|\left(\cdot\left|r q_{-} \cdot\right| \wedge \mid\right)$ & $10(\Gamma / \Lambda)$ & s-V \\
\hline$\cdot / T r(\cdot / \cdot V-\cdot / T V)$ & $\cdot \mid \Phi \psi(\cdot / r \Lambda-\cdot \mid \Delta \Phi)$ & $\operatorname{TF}(F / Q)$ & مساوى و بيشتر از 1 \\
\hline
\end{tabular}


كوموربيديتى جارلسون در خندين مطالعه در ارتباط با بيماران

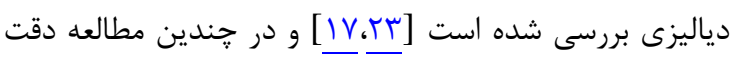

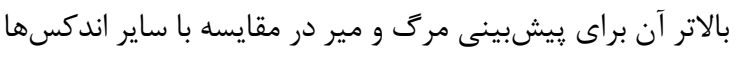

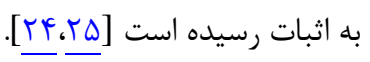

در اين مطالعه براى بررسى فاكتورهاى ييشكَويى كننده مرك الهات

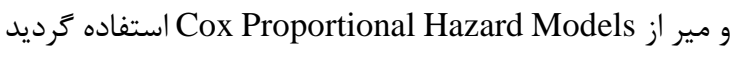

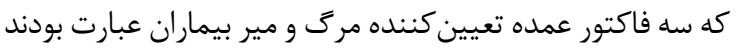

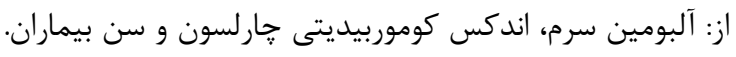

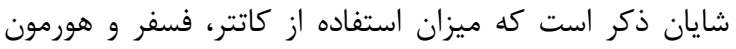

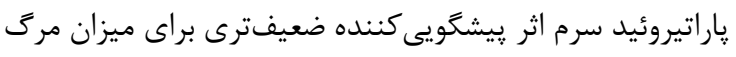

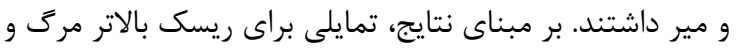

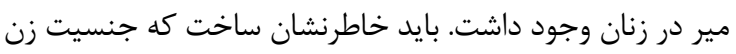

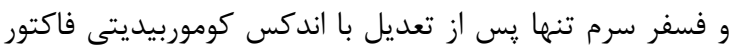

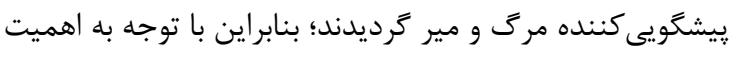

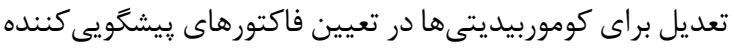

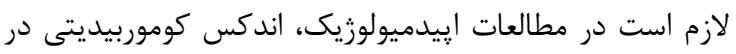

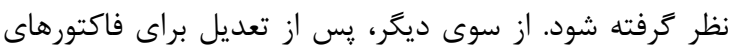

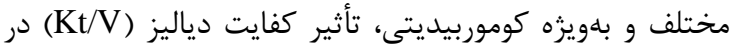

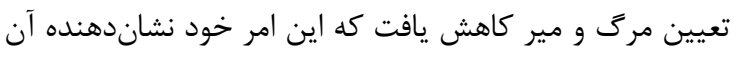

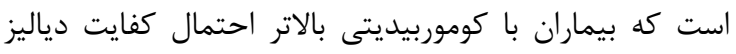

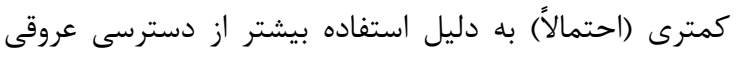

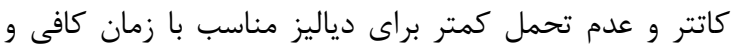

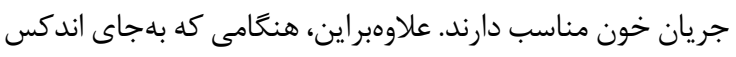

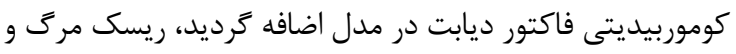

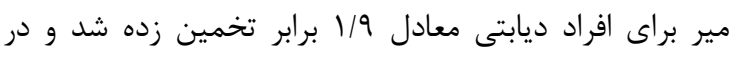

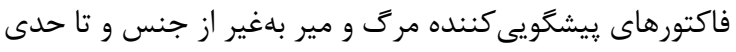

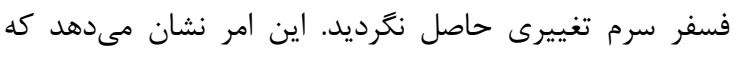

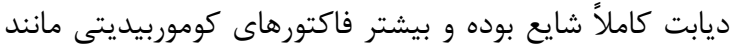
سكته قلبى، نارسايى قلبى، حوادث مغزى - عروقى و بيمارى هائ دئي

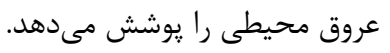

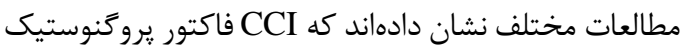
مناسبى براى بيماران دياليزى بوده و براى بررسى كوموربيديدي

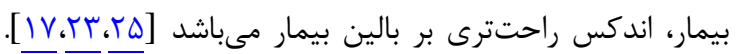

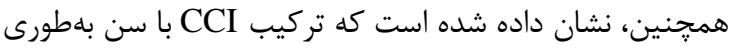

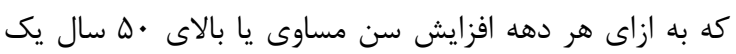

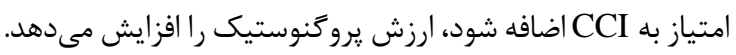

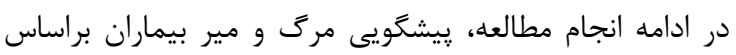

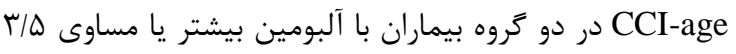

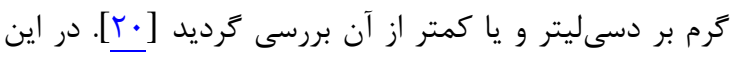

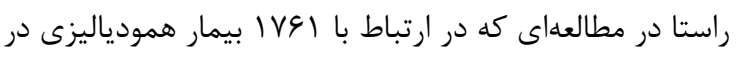

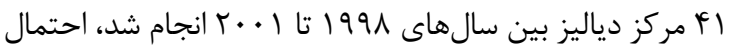

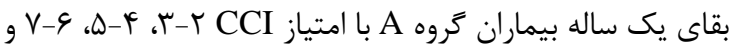

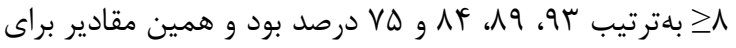

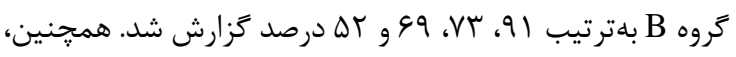

منحنى بقاى كايلان - ماير بيماران با امتيازهاى مختلف كروه و A د A شكل ا نشان داده شده است.

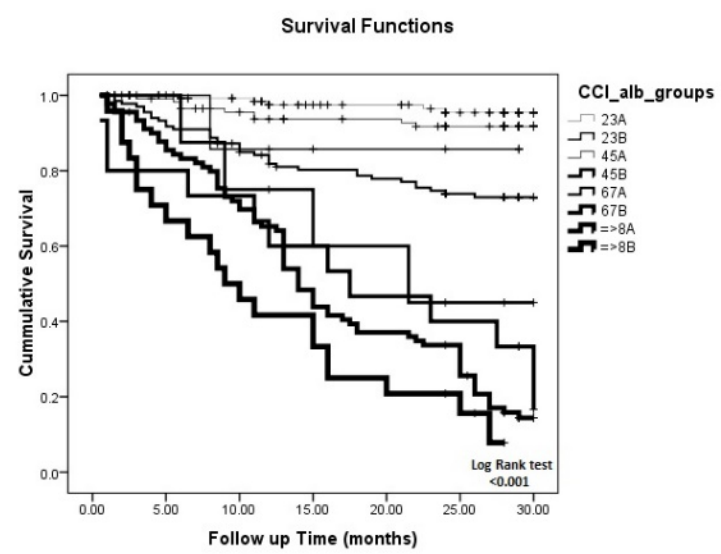

شكل ا: منحنى بقاى كايلان- ماير براى درجات مختلف اندكس كوموربيديتى خارلسون، سن و آلبومين سرم دران

بحث

بيشآكاهى بيماران دياليزى با وجود بهبود كيفيت دياليز

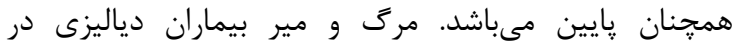

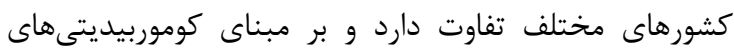
زمينهاى شامل: ديابت و بيمارىهاى قلبى - عروقى، سن بيماران،

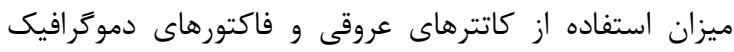

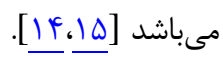

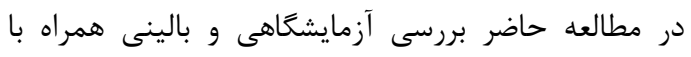

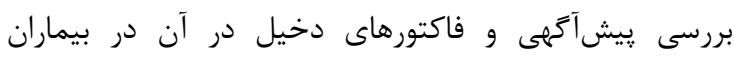

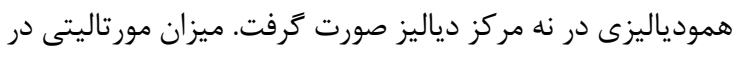

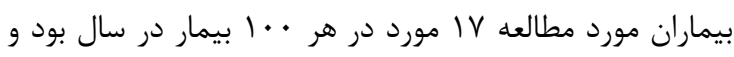

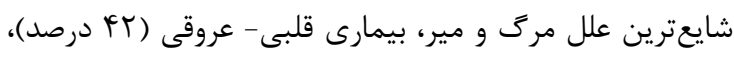

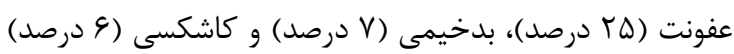

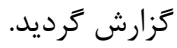
نشان داده شده است كه تعداد بالاتر كوموربيديتى باعث

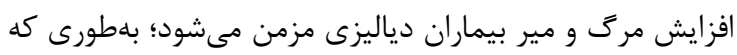

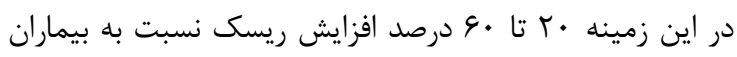

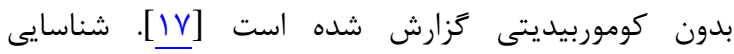

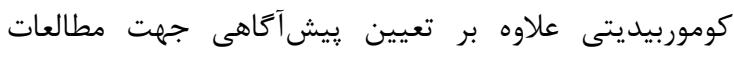

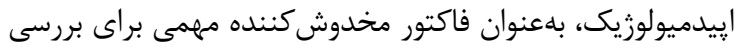

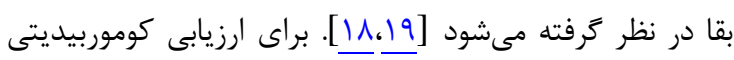

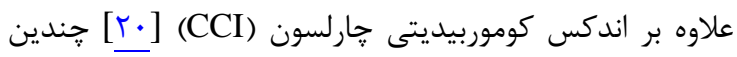

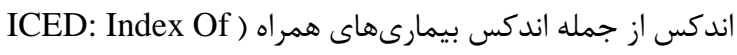
(Co-Existent Diseases

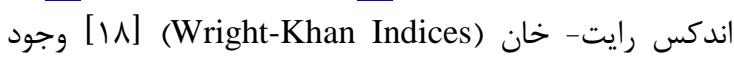

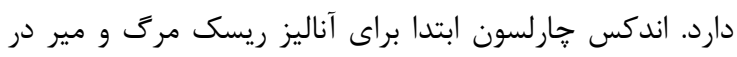

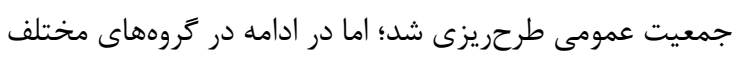

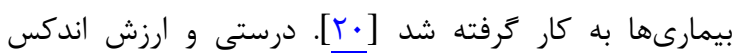


مخدوشكننده ناشناخته مىباشد. محدوديت ديخر نيز عدم

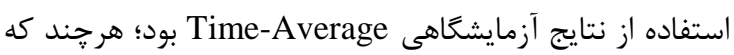
از متوسط سه آزمايش آخر قبل از مطالعه استفاده كرديد.

\section{نتيجه تيرى}

با وجود ييشرفتهاى ايجادشده در درمان، هنوز هم بيماران

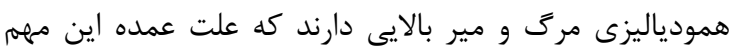

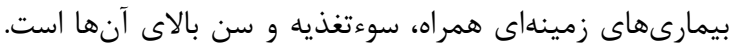

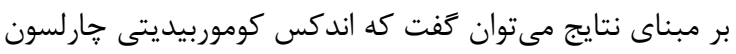

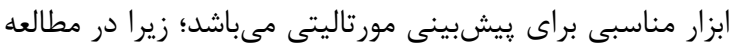

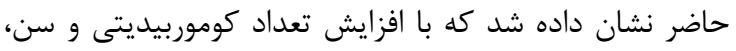

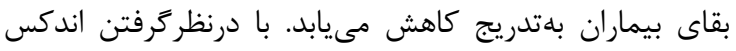

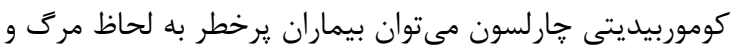

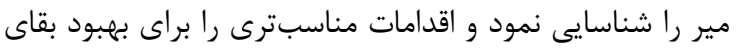
آنها انجام داد.

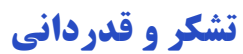

مقاله حاضر بركرفته از يك مطالعه مولتى سنتر مصوب

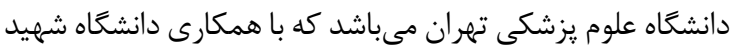

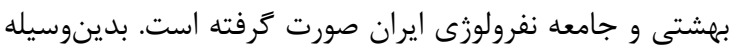

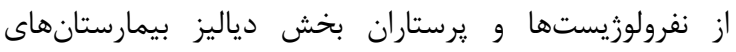
شريعتى، مدرس، هاشمىنزاد، فيروزگر، شهداى هفتم تير، خيريه

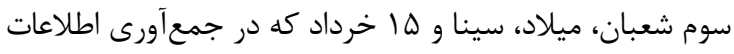

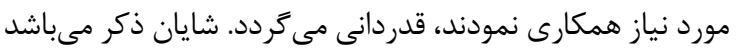
كه هيجَّنه تعارض منافعى در اين مطالعه كَزارش نكرديده است.

\section{REFERENCES}

1. Soleymanian T, Kokabeh Z, Mahjoub A, Ramaghi R, Argani $\mathrm{H}$. Clinical outcomes and quality of life in hemodialysis diabetic patients versus non-diabetics. $J$ Nephropathol. 2017;6(2):81-9. PMID: 28491858 DOI: 10.15171/jnp.2017.14

2. Soleymanian T, Sheikh V, Tareh F, Argani H, Ossareh S. Hemodialysis vascular access and clinical outcomes: an observational multicenter study. J Vasc Access. 2017;18(1):3542. PMID: 27791255 DOI: $10.5301 /$ jva.5000610

3. Soleymanian T, Niyazi H, Noorbakhsh Jafari Dehkordi S, Savaj S, Argani H, Najafi I. Predictors of clinical outcomes in hemodialysis patients: a multicenter observational study. Iran J Kidney Dis. 2017;11(3):229-36. PMID: 28575884

4. Keane WF, Collins AJ. Influence of co-morbidity on mortality and morbidity in patients treated with hemodialysis. Am J Kidney Dis. 1994;24(6):1010-8. PMID: 7985662

5. Kopple JD. Nutritional status as a predictor of morbidity and mortality in maintenance dialysis patients. ASIO J. 1997;43(3):246-50. PMID: 9152503

6. Lowrie EG. Acute-phase inflammatory process contributes to malnutrition, anemia, and possibly other abnormalities in dialysis patients. Am J Kidney Dis. 1998;32(6 Suppl 4):S10512. PMID: 9892376

7. Foley RN, Parfrey PS, Sarnak MJ. Clinical epidemiology of cardiovascular disease in chronic renal disease. Am J Kidney Dis. 1998;32(5 Suppl 3):S112-9. PMID: 9820470

8. Genovesi S, Valsecchi MG, Rossi E, Pogliani D, Acquistapace I, De Cristofaro V, et al. Sudden death and associated factors in a historical cohort of chronic haemodialysis patients. Nephrol Dial Transplant. 2009;24(8):2529-36. PMID: 19293137 DOI:

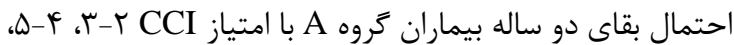

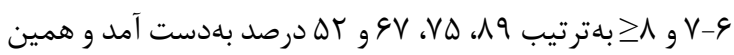

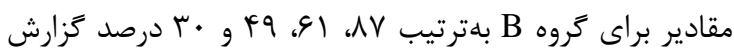
كشت [rq]

مطالعات نشان دادهاند كه تخمين ميزان بقاى بيماران هم براى تصميم گيرى شروع دياليز و هم براى شناسايى بيماران با خطر بالاى مرگ و مير جهت قييخيرى و درمان مناسبتر آنها مفيد مىباشد [•r، 19]1]. در اين مطالعه احتمال بقاى يكى ساله

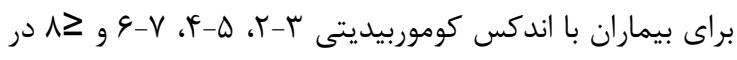
صورتى كه آلبومين سرم مساوى يا بيشتر از هاس ميلى

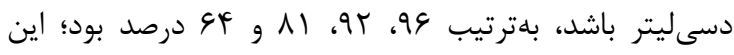
درحالى است كه همين مقادير در صورت وجود آلبومين سرم كمتر از ه/ درصد مىباشند. علاوهبراين، بقاى دو ساله براى مقادير فوق در

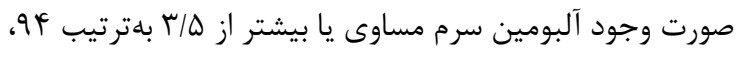

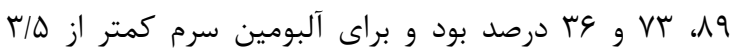

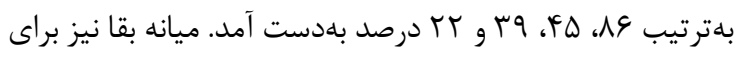

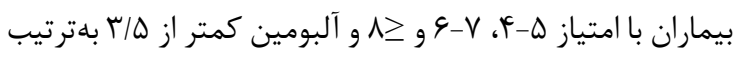

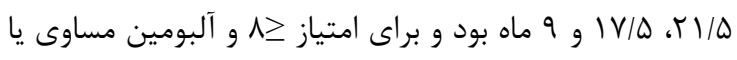

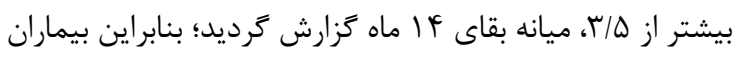
با آلبومين يايينتر و سوءتغذيه بيشتر، احتمال مرگ و و مير بيشترى دارند.

در نهايت در ارتباط با محدوديتهاى مطالعه حاضر مىتوان

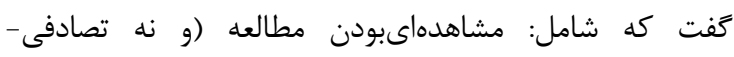

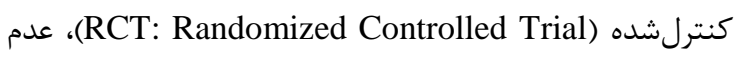
درنظركرفتن باقى مانده عملكرد كليه و احتمالاً ساير فاكتورهاى

10.1093/ndt/gfp104

9. de Jager DJ, Grootendorst DC, Jager KJ, van Dijk PC, Tomas LM, Ansell D, et al. Cardiovascular and noncardiovascular mortality among patients starting dialysis. JAMA. 2009;302(16):1782-9. PMID: 19861670 DOI: 10.1001/ jama.2009.1488

10. Wakasugi M, Kazama JJ, Yamamoto S, Kawamura K, Narita I. Cause-specific excess mortality among dialysis patients: comparison with the general population in Japan. Ther Apher Dial. 2013;17(3):298-304. PMID: 23735145 DOI: 10.1111/j.1744-9987.2012.01144.x

11. Wanner C, Drechsler C, Krane V. C-reactive protein and uremia. Semin Dial. 2009;22(4):438-41. PMID: 19708997 DOI: 10.1111/j.1525-139X.2009.00596.x

12. Powe NR, Jaar B, Furth SL, Hermann J, Briggs W. Septicemia in dialysis patients: incidence, risk factors, and prognosis. Kidney Int. 1999;55(3):1081-90. PMID: 10027947 DOI: 10.1046/j.1523-1755.1999.0550031081.X

13. Weng PH, Hung KY, Huang HL, Chen JH, Sung PK, Huang KC. Cancer-specific mortality in chronic kidney disease: longitudinal follow-up of a large cohort. Clin $J \mathrm{Am}$ Soc Nephrol. 2011;6(5):1121-8. PMID: 21511834 DOI: 10.2215/CJN.09011010

14. Collins AJ, Foley RN, Herzog C, Chavers BM, Gilbertson D, Ishani A, et al. Excerpts from the US renal data system 2009 annual data report. Am J Kidney Dis. 2010;55(1 Suppl 1):S1420. PMID: 20082919 DOI: 10.1053/j.ajkd.2009.10.009

15. Goodkin DA, Bragg-Gresham JL, Koenig KG, Wolfe RA, Akiba T, Andreucci VE, et al. Association of comorbid 
conditions and mortality in hemodialysis patients in Europe, Japan, and the United States: the dialysis outcomes and practice patterns study (DOPPS). J Am Soc Nephrol. 2003;14(12):3270-7. PMID: 14638926

16. Goodkin DA, Young EW, Kurokawa K, Prütz KG, Levin NW. Mortality among hemodialysis patients in Europe, Japan, and the United States: case-mix effects. Am J Kidney Dis. 2004;44(5 Suppl 2):16-21. PMID: 15486869

17. van Manen JG, Korevaar JC, Dekker FW, Boeschoten EW, Bossuyt PM, Krediet RT, et al. How to adjust for comorbidity in survival studies in ESRD patients: a comparison of different indices. Am J Kidney Dis. 2002;40(1):82-9. PMID: 12087565 DOI: 10.1053 /ajkd.2002.33916

18. Khan IH, Catto GR, Edward N, Fleming LW, Henderson IS, MacLeod AM. Influence of coexisting disease on survival on renal-replacement therapy. Lancet. 1993;341(8842):415-8. PMID: 8094182

19. Chandna SM, Schulz J, Lawrence C, Greenwood RN, Farrington K. Is there a rationale for rationing chronic dialysis? A hospital based cohort study of factors affecting survival and morbidity. BMJ. 1999;318(7178):217-23. PMID: 9915728

20. Charlson ME, Pompei P, Ales KL, MacKenzie CR. A new method of classifying prognostic comorbidity in longitudinal studies: development and validation. $J$ Chronic Dis. 1987;40(5):373-83. PMID: 3558716

21. Athienites NV, Miskulin DC, Fernandez G, Bunnapradist S,
Simon G, Landa $M$, et al. Comorbidity assessment in hemodialysis and peritoneal dialysis using the index of coexistent disease. Semin Dial. 2000;13(5):320-6. PMID: 11014695

22. Davies SJ, Russell L, Bryan J, Phillips L, Russell GI. Comorbidity, urea kinetics, and appetite in continuous ambulatory peritoneal dialysis patients: their interrelationship and prediction of survival. Am J Kidney Dis. 1995;26(2):35361. PMID: 7645541

23. Hall SF. A user's guide to selecting a comorbidity index for clinical research. J Clin Epidemiol. 2006;59(8):849-55. PMID: 16828679 DOI: 10.1016/j.jclinepi.2005.11.013

24. Di Iorio B, Cillo N, CirilloM, De Santo NG. Charlson comorbidity index is a predictor of outcomes in incident hemodialysis patients and correlates with phase angle and hospitalization. Int J Artif Organs. 2004;27(4):330-6. PMID: 15163067

25. Fried L, Bernardini J, Piraino B. Charlson comorbidity index as a predictor of outcomes in incident peritoneal dialysis patients. Am J Kidney Dis. 2001;37(2):337-42. PMID: 11157375 DOI: $10.1053 / a j k d .2001 .21300$

26. Miskulin DC, Martin AA, Brown R, Fink NE, Coresh J, Powe $\mathrm{NR}$, et al. Predicting one-year mortality in an outpatient hemodialysis population: a comparison of comorbidity instruments. Nephrol Dial Transplant. 2004;19(2):413-20. DOI: $10.1093 /$ ndt/gfg571 